\title{
LO PÚBLICO Y LO PRIVADO EN EL ESPACIO PÚBLICO MALECÓN SIMÓN BOLÍVAR: RELACIONES DE PODER Y GIUDADANÍA ${ }^{1}$
}

\author{
THE PUBLIC AND THE PRIVATE IN THE PUBLIC \\ SPACE MALECÓN SIMÓN BOLÍVAR: RELATIONS OF \\ POWER AND CITIZENSHIP
}

\begin{abstract}
Marcela Blacio Valdivieso
Arquitecta urbanista por la Universidad de Guayaquil. Se graduó de profesora en la UTPL con mención en Administración y Supervisión Educativa. Obtuvo una maestría en Antropología del Desarrollo en la Universidad del Azuay. Es candidata a doctora en el Doctorado de Arquitectura con mención en Urbanismo, de la Facultad de Diseño, Arquitectura y Urbanismo de la Universidad de Buenos Aires y en el doctorado de Antropología Social de la Universidad de San Martín, en Buenos Aires. Ha impartido seminarios y cursos sobre Gestión del Riesgo en la Universidad Católica Santiago de Guayaquil. Ha sido docente en el doctorado del Instituto de Diplomacia de la Universidad de Guayaquil. Actualmente labora como docente de pregrado y Coordinadora de la Maestría en Planificación Territorial y Gestión Ambiental de la Universidad de Guayaquil.

mblacio@hotmail.com
\end{abstract}

Fecha de recepción: 23 de abril, 2018 / Aceptación: 18 de mayo, 2018.

DAYA. Diseño, Arte y Arquitectura. Número 4, Diciembre 2017 - Junio 2018, pp. 65 - 79, ISSN 2550-6609 (print) - E-ISSN 2588-0667 (digital) 


\section{Resumen}

La gentrificación es un concepto que ha sido aplicado esencialmente a las áreas urbanas, pero se ha exceptuado en su análisis a los espacios públicos. Nuestro planteamiento está centrado en una especial forma de analizar la gentrificación en áreas no residenciales. Una de estas áreas es el espacio público conocido como Malecón Simón Bolívar de la ciudad de Guayaquil. Queremos demostrar que la gentrificación que ha operado en este proyecto emblemático de la regeneración urbana guayaquileña es esencialmente comercial y cultural. Para ello emprendimos tanto una investigación documental sobre la historia de Guayaquil, su puerto y su malecón, que ahonda en aspectos sociales, económicos, culturales y políticos, como una investigación de campo con encuestas, entrevistas, y fotoetnografías, centrada en probar los mecanismos que, en forma de dispositivos e imaginarios, procesan una gentrificación sui géneris en el espacio público. Los resultados dan cuenta de una apropiación privada, procesada a lo largo de veinte años, en forma de una oferta para el consumo comercial y cultural en el espacio que debe ser de todos. Así mismo, informa sobre dispositivos financieros, urbanos, cívicos y sociales y unos imaginarios sociales que profundizan la privatización del espacio público.

\section{Palabras clave}

Espacio público, espacio privado, gentrificación comercial y cultural, modelo de gestión, regeneración urbana, relaciones de poder, revalorización inmobiliaria.

\section{Abstract}

Gentrification is a concept that has been applied essentially to urban areas except on its analysis of public spaces. Our approach is focused on a special way of analyzing gentrification in non-residential areas. One of these areas is the public space known as Malecón Simón Bolívar in the city of Guayaquil. We want to demonstrate that the gentrification that has operated in this emblematic project of Guayaquil urban regeneration is essentially commercial and cultural. To do this we did a documentary research -on the history of Guayaquil, its port and its boardwalk, delving into social, economic, cultural and political aspects- and a field research- survey, interviews, and photoetnography- focused on testing the mechanisms that, in form of devices and imaginaries, they process a sui generis gentrification in the public space. The results of this research show a private appropriation, processed over 20 years, in the form of an offer for commercial and cultural consumption in the space that should belong to everyone. Likewise, of some devices: financial, urban, civic and social and some social imaginaries that deepen the privatization of public space.

\section{Keywords}

Commercial and cultural gentrification, management model, power relations, public space, private space, real estate revaluation, urban regeneration. 


\section{Introducción}

En la primera parte hacemos un análisis del desarrollo poblacional de Guayaquil para inicios del siglo XX y el proceso de abandono del centro de la ciudad por una parte de los sectores altos, para la década del veinte hacia el Barrio del Centenario. Las mejoras y la ampliación del Malecón, el puerto, las aduanas, los muelles, el Paseo de las Colonias, el Hemiciclo de la Rotonda, los barrios del sur, el Mercado Sur. Para la mitad del siglo se cambia el puerto al sur, se construye el Puente de la Unidad Nacional, se abren nuevos programas de vivienda y ocurre un segundo abandono de sectores altos del centro de la ciudad hacia las nuevas áreas al norte. El Malecón Simón Bolívar resistió estos cambios, pero sufrió un abandono de ciertas áreas, especialmente de la zona norte donde estaban las aduanas, si bien seguían funcionando como área pública para el paseo. El boom petrolero de los setenta permitió que se inauguraran obras y edificaciones en el centro de la ciudad, pero el abandono residencial cobró factura: ocurrió una pérdida del valor de las edificaciones residenciales, bancarias, comerciales y de oficinas.

Hasta fines del noventa, cuando el socialcristianismo asumió el gobierno local, se iniciaron obras y nuevas acciones. Para el efecto, se aplicó un modelo privatizador que va de las unidades ejecutoras al modelo de gestión y se inauguró la regeneración urbana a partir de una alianza público-privada que convirtió al Malecón Simón Bolívar en el Proyecto Malecón 2000. A partir de ese momento se abrió un proceso de gentrificación cultural y comercial de su espacio público más emblemático, el Malecón. Recuperar este espacio para la ciudadanía implica una empresa que demanda la participación e integración del malecón y el centro; demanda abrir rejas y generar espacios que conviertan al Malecón en el lugar de paseo y esparcimiento, demanda liberar al Malecón del tráfico vehicular, y que el río Guayas se constituya en la vía de transporte fluvial y el medio de esparcimiento y deporte.

\section{El puerto y el Malecón para inicios del siglo XX}

La estructura urbana de la ciudad estuvo determinada física y socialmente por su condición geográfica de golfo y puerto del Pacífico y por el rol que ejercía el comercio en la ciudad. Del puerto de Guayaquil salía el 90\% de la producción cacaotera y alrededor del $80 \%$ del total de las exportaciones del país. Los sectores económicamente solventes de Guayaquil, asentados en la zona central paralela al río y alrededor de las iglesias, fueron poco a poco desplazando población de sectores populares que se habían asentado en la sabana cuando bajaron de la ciudad vieja a la nueva. Lo hicieron, entre otros mecanismos, a partir de las ordenanzas de construcción que tenían como objetivo preservar las edificaciones frente a los incendios.

Para 1920 grupos de sectores altos efectuaron el primer traslado del centro al Barrio del
Centenario, al sur de Guayaquil, barrio que toma el nombre del primer centenario de la independencia de la ciudad. En 1931 se construyó en el malecón el Paseo de las Colonias, en el sector comprendido entre la calle Francisco de P. Icaza y la Av. 10 de Agosto, ajardinado y con un mobiliario urbano de piletas, monumentos y ornamentaciones donadas por las colonias extranjeras asentadas en la ciudad. En 1938 se inauguró el Hemiciclo de La Rotonda. Las mejoras y ampliaciones del malecón se efectuaron cada año, entre 1935 y 1937, para ir ganando terreno al río e incrementar su ancho. Los muelles privados, impulsados por los grandes comerciantes importadores y exportadores frente a sus almacenes en la Calle de la Orilla, se construyeron bajo la figura legal de la concesión por determinada cantidad de años para luego pasar a ser manejados por la administración pública.

En 1936 se concretaron las nuevas instalaciones de la aduana y su muelle cerca de la Plaza Colón, así como las vías del ferrocarril de carga 
impulsado a vapor que llevaba y traía mercadería desde los diversos muelles privados que, en número de veintiocho, se construyeron a lo largo del borde del Guayas. En el norte del Malecón se asentó el Barrio Las Peñas, en las laderas del cerro Santa Ana. Se reconstruyeron sus viviendas luego del incendio grande del 5 y 6 de octubre de 1896. Las partes altas de la ladera fueron pobladas por sectores populares. Atrás de la Calle de la Orilla (hoy calles Panamá y Rocafuerte) se ubicaron las bodegas cacaoteras.

Los otros barrios populares estaban al sur donde se asentaron los astilleros y el Barrio del Astillero, con la descarga de maderos que venían por la red fluvial. Hubo zonas residenciales de sectores medios y medio altos como manchas que se mezclaban con sectores populares que trabajaban en las fábricas apostadas en la orilla. Esta zona contaba con sus propios muelles para el atraque de buques que debían ser carenados o para la construcción de barcos nuevos. También estaban los muelles para el comercio interprovincial y de cabotaje.

El Mercado Sur, mercado de abastos y comedor popular, se concretó en 1907. El atracadero de canoas frente al mercado se formó en los bajos, donde se fondeaban las embarcaciones que venían de plantaciones vecinas con productos para vender y también para hacer compras, las que conformaban el mercado de la orilla; $y$, así mismo, estaban las de los agricultores que arribaban con productos para comercializar. Otro muelle lo usaban los pescadores que traían frutos del mar o de los ríos para la venta en los mercados, especialmente al de la orilla.

La ordenanza municipal de 1936 denominó al Malecón de Guayaquil Simón Bolívar, el sitio estaba limitado por la Plaza Colón al norte y por la Av. Olmedo al sur. Cinco años más tarde se construyó el Club de La Unión en Malecón y Av. Olmedo y en 1950 se construyó una plazoleta y se colocó el monumento a José Joaquín de Olmedo frente al Club². El Malecón cumplía la función de área pública y de paseo cuando las actividades del puerto bajaban de intensidad, especialmente al caer la tarde. Con el proceso de sedimentación del río Guayas, el puerto, que operaba en la parte norte del malecón, tuvo problemas en la movilización de embarcaciones, especialmente las nuevas naves de comercio exterior. Además de que el banano, el nuevo producto agrícola de exportación, requería condiciones de embalaje y bodegaje especiales.

La ciudad empezó a buscar el lugar para trasladar el puerto. En 1958 se emitió un decreto de creación de la Autoridad Portuaria de Guayaquil, $A P G$, entidad paraestatal autónoma de derecho privado cuyo fin era el planeamiento, la financiación, la ejecución, las operaciones, los servicios y las facilidades tanto en el actual puerto de Guayaquil como en el Puerto Nuevo y de todas las obras portuarias que se construyeren dentro de su jurisdicción. Su fin concreto fue gestionar un préstamo del Banco Mundial por trece millones de dólares para la construcción del nuevo puerto. En 1963 dicha Terminal fue inaugurada y el malecón se quedó sin la actividad portuaria que había sido su factor dinamizador y su atractivo (Fernández y Fernández, 2007). Con la nueva ubicación del puerto desaparecieron las actividades colaterales, trámites aduaneros, bodegas, servicios y muchas oficinas cambiaron de actividad.

En el viejo puerto seguían atracando naves de mediano o poco calado, pero esta actividad poco a poco fue disminuyendo. Había lanchas que cruzaban el río Guayas hacia la orilla opuesta donde se asentaba la población de Durán, Ilevaban paseantes o pasajeros que tomaban el tren en tránsito a la sierra. Pero el grueso de los usuarios del transporte fluvial lo constituían los habitantes de Durán que iban y venían a sus trabajos 0 a realizar trámites en Guayaquil.

Desde la década del sesenta, algunas familias dueñas de edificaciones importantes en el centro iniciaron su traslado a las nuevas urbanizaciones al norte de la ciudad; las de sectores medios, residentes 0 arrendatarias se dirigieron al sur. El centro urbano se fue abandonando paulatinamente como zona residencial de sectores altos y medio altos, aun cuando quedaron algunos sectores conformados por parejas mayores. Durante el día había un uso intensivo comercial, bancario y de gestión administrativa, que iba disminuyendo al término de la jornada la- 
boral diaria. Se construyó el puente de la Unidad Nacional que atraviesa los ríos Daule y Babahoyo, los dos afluentes del Guayas que conectan la Sierra con la Costa, con una longitud de $870 \mathrm{~m}$ el que cruza el río Daule y de 1995 m el del río Babahoyo. Con el puente se fue terminando el transporte fluvial y se eliminó el planchón (gabarra) que llevaba por el río los automóviles que se dirigían hacia la Sierra central, norte y sur.

En la zona céntrica y frente al río ocurrieron una serie de cambios -a partir del traslado del puerto y el nuevo Puente de la Unidad Nacional- junto con una modificación en la composición residencial. A este fenómeno de abandono residencial de sectores sociales altos y medio altos en el centro se sumó el hecho de que, a partir de esta época, junto con los nuevos programas de vivienda dirigidos a estos sectores, en el norte de la ciudad se implementaron proyectos descentralizadores de servicios y comercios: sucursales de bancos, negocios, servicios de restaurantes y hoteles y la construcción de los llamados malls o centros comerciales, lo que ahondó el abandono del centro e incrementó sus problemas de inseguridad ${ }^{3}$ especialmente en las noches.

Las distintas administraciones municipales desarrollaron planes o programas urbanos, pero no los concretaron a través de sus mecanismos pertinentes: ordenanzas y disposiciones que permitieran ejecutarlos. Conocían el diagnóstico de la zona central de la ciudad y las posibles medidas que debían emprenderse, tal como lo expresa la Ordenanza Preventiva de $1975^{4}$. Este Esquema Urbano y Ordenanza ya proponía la necesidad de la renovación urbana del Centro y otro destino para el Malecón Simón Bolívar donde los muelles y el transporte fluvial cobrarían importancia. Pero estas políticas no se cumplieron. Tampoco iniciaron acciones para evitar el abandono del centro y se aprobaron los proyectos de nuevas urbanizaciones sin considerar los efectos que traerían no solo en el área céntrica, sino también en las nuevas zonas de expansión.

A partir de 1972, con los ingresos de la explotación y exportación de petróleo, se abrió una época de modernización promovida por el Estado.
En esos años, la ciudad duplicó su extensión geográfica y su población: alcanzó los 850 mil habitantes en 1974. Los migrantes que fueron arribando se asentaron y ocuparon el suburbio oeste (Blacio et al., 1983). Solo la profundidad de los esteros impidió que avanzara el crecimiento urbano en esta dirección. El boom petrolero permitió que propietarios de viejas edificaciones de la zona central las remodelaran, rehabilitaran o demolieran a favor de la construcción de modernos edificios de oficinas y alguno que otro residencial, hecho que provocó un perjuicio del patrimonio cultural de la ciudad.

En la zona norte del malecón, la presencia de la ESPOL dio lugar a que docentes y estudiantes se instalaran en los edificios de la antigua aduana, y también se construyeron restaurantes en algunos muelles abandonados. Las áreas contiguas comenzaron a servir de garajes para automóviles de la gente que iba a comer, vivía, trabajaba o realizaba trámites en el centro. En el extremo sur, en cambio, muchos edificios de departamentos convirtieron su parte baja en almacenes y restaurantes, y las plantas altas se transformaron en bodegas de mercaderías introducidas ilegalmente por el río, o en espacios para el trabajo de maquilas para la confección de indumentarias que eran vendidas en la Bahía como mercadería de contrabando. Incluso uno de los hoteles más importantes, el Humboldt Internacional, de primera categoría en su tiempo, cambió su ocupación de servicio para la venta de productos de contrabando.

El área céntrica concentró funciones de gestión político-administrativa- financiera y comercial de la ciudad con la municipalidad, la gobernación, las casas matrices de los bancos, el mercado de víveres, los grandes almacenes del comercio formal, la famosa Bahía, dedicada a la venta de productos de contrabando que entraban al puerto, y el comercio informal en veredas y calles. El Malecón continuó siendo el lugar de paseo y compras de amplios sectores populares y medios. Todo esto convocaba diariamente a miles de pobladores que utilizaban el sector central y el sur del malecón como hito referencial y como área de circulación y conexión peatonal para dirigirse a las distintas zonas del casco central, 
así como para descansar, para los encuentros, para pasear aprovechando la brisa del río, etc. (Fernández y Fernández, 2007). Entre el Malecón Simón Bolívar y el área central existían determinadas características: transparencia, penetrabilidad, permeabilidad, apropiación del espacio, variedad, diversidad y legibilidad; era un espacio público que, aun sin el mantenimiento necesario, atraía a la población para su uso.

El Malecón Simón Bolívar y la Avenida 9 de Octubre eran los sitios de paseo de lunes a viernes para los sectores medios y medio altos. Los fines de semana, en cambio, lo utilizaban amplios sectores populares, especialmente las trabajadoras domésticas que contaban con esos días de descanso. Estos grupos venían de las zonas de invasiones en el suroeste, en el norte y en el sur, así como de los cerros El Carmen y Santa Ana. También se acercaban pobladores de las nuevas urbanizaciones residenciales, de sectores medios y populares localizadas al norte y sur de la ciudad, desarrollados por la Junta Nacional de la Vivienda y Banco de la Vivienda y los programas privados de viviendas populares o de interés social. No obstante, por las noches las áreas bajas de los cerros de El Carmen y Santa Ana, así como parte de la zona frente al Cementerio y del Parque de La Madre cercanas al Malecón, eran foco de delincuentes.

\section{El ambiente político de fines del siglo XX}

Para la década del setenta, la bonanza petrolera fue de tal envergadura que intervinieron los militares y derrocaron al presidente electo Velasco Ibarra porque en su último período (el quinto) se declaró dictador y destituyó, entre otros, a las autoridades de Guayas y Guayaquil, prefecto y alcalde, que se perfilaban como posibles candidatos presidenciales. El golpe conocido como El Carnavalazo puso en el poder a un gobierno revolucionario nacionalista que duró dos períodos, uno de 1972 a 1976 y el otro de 1976 a 1978, que preparó un plan de retorno a la democracia y expidió una nueva Constitución. Los ingresos petroleros en esta dictadura constituyeron un capitalismo de Estado y un modelo económico de sustitución de importaciones.
El retorno a la democracia inició un nuevo período constitucional bajo las presidencias de Jaime Roldós (1979-1981), Oswaldo Hurtado (1981-1984), León Febres Cordero Rivadeneira (1984-1988), Rodrigo Borja (1988-1992) y Sixto Durán Ballén (1992-1996). En todos estos años, las obras y las principales decisiones del país estuvieron centradas en el nivel nacional. No obstante, Jaime Roldós y León Febres Cordero, al ser guayaquileños, impulsaron acciones para la ciudad desde sus presidencias. Se debe remarcar que desde 1947 hasta 1992 -cuarenta y cinco años- el gobierno local en Guayaquil tuvo 37 alcaldes, casi un alcalde por año, y durante la dictadura (1972-1978), pasaron 8 alcaldes, un promedio de menos de uno por año. Ganar la alcaldía de Guayaquil implicaba hacerse de un botín económico y político importante pero fugaz.

Esta situación marcó un grado alto de inestabilidad administrativa y se puede leer, sin temor a equivocarse, que la alcaldía de Guayaquil era una tienda política del gobierno nacional de turno, sea este democrático o dictatorial. Era algo parecido a la situación de dependencia de la ciudad durante la colonia, la Gran Colombia y en los inicios de la República. Después de 1978, volvieron también las elecciones para los gobiernos seccionales y se abrió el camino del populismo en Guayaquil, cuyos exponentes más conspicuos fueron los hermanos Abdalá Bucaram (1984-1985) y Elsa Bucaram (1988-1991). La gestión administrativa populista no pudo solucionar los más graves problemas de la ciudad que se venían arrastrando de décadas anteriores, a los que se sumaron escándalos de corrupción, especialmente en las dos administraciones de los hermanos Bucaram.

Hemos considerado necesario sintetizar el periodo de fines del siglo XX tanto a nivel nacional como cantonal, porque nos permitirá comprender el ambiente político y las condiciones que antecedieron a las elecciones de Febres Cordero a la alcaldía (1992) y, a partir de él, la forma en que se sucedieron veinte años de gobierno socialcristiano en Guayaquil cuyo modelo de regeneración urbana, que se inició con el Proyecto Malecón 2000, constituyó su emblema de acción. 


\section{De la regeneración urbana a la gentrificación}

Estos antecedentes ayudan a comprender el contexto social y político de la ciudad más poblada y de mayor extensión geográfica del Ecuador. León Febres Cordero, expresidente de la República (1984-1988), Ilegó cuatro años después a la alcaldía de Guayaquil para el período 1992-1996; luego fue reelecto de 1996 al 2000. En su primera administración tomó la decisión de cerrar la Municipalidad por noventa días para "poner la casa en orden". En 1994 UN-Hábitat dio asistencia técnica a la Municipalidad de Guayaquil para formular el Plan de Desarrollo Municipal y de Obras Públicas.

El Gobierno local contrató un nuevo catastro en coordinación con la universidad. A partir de allí se procedió a legalizar los terrenos en los sectores de invasiones. Hasta antes, las acciones fueron siempre un dispositivo de control de los gobiernos populistas anteriores que habían hecho de ellas un recurso de campaña para las elecciones, sean locales 0 nacionales, pero que no pasaron más que de la posesión de los predios. Lo que hizo la nueva alcaldía fue convertir a cientos de miles de familias asentadas en terrenos de invasiones desde la década del veinte en propietarias de su pedazo de tierra en los sectores marginales e integrar a esa población al pago de impuestos prediales, proceso que continúa hasta hoy.

Febres Cordero inició la construcción y reconstrucción de la red de mercados, combatió el comercio informal persiguiendo a los vendedores ambulantes a quienes confiscó sus mercaderías y tomó presos; construyó pasos a desnivel, distribuidores de tráfico, mejoró la conectividad de las vías; privatizó la recolección de basura, reorganizó los servicios de agua potable, alcantarillado sanitario y pluvial; se rediseñaron y mejoraron los parques y estableció una alianza público-privada para su mantenimiento. El gobierno seccional bajo su mandato pasó a ser un organismo que auto gestionó parte de su presupuesto y negoció con el entonces presidente de la república, Sixto Durán Ballén, las competencias y el presupuesto que viene del Estado central. La alcaldía de Guayaquil abrió esta etapa de obras de mejoramiento urbano aplicando dispositivos técnico-financieros de contratación pública de obras y servicios con entidades privadas a través de las Unidades Ejecutoras bajo el eslogan "Guayaquil vive por ti", con una intensa campaña publicitaria que enfatizó el desarrollo de Guayaquil desde y por los guayaquileños.

Un programa menor, la remodelación de parques con el apoyo de la empresa privada, dio un vuelco a la gestión administrativa de Febres Cordero al inicio de su segundo y último período como alcalde. Esta vez el Banco La Previsora, con el apoyo de la Oxford Brookes University, presentó a la alcaldía la imagen objetivo del mejoramiento del Malecón con el propósito de volver a asignar valor al área central: la regeneración urbana (Wong, 2005). Esa alianza del municipio con los bancos se convirtió en el Proyecto Malecón 2000, un dispositivo de regeneración urbana operado con fondos estatales (del gobierno central y del gobierno seccional) y ciudadanos (aporte del $25 \%$ de los impuestos individuales y empresariales, en el fondo estatales) con mecanismos operativo-financieros propios de la empresa privada.

Un contrato de comodato entre la Fundación Malecón 2000 (en adelante FM2000) y el Municipio de Guayaquil el 30 de enero de 1997 concesionó por 99 años el Malecón Simón Bolívar de Guayaquil (en adelante Malecón) a la Fundación para que diseñe, ejecute y administre el Proyecto Malecón 2000 (en adelante PM2000). En el año 2096 deberá volver a la administración pública local, aunque en el contrato se estipula que puede extenderse otros 99 años más. De este modo se inauguró lo que podría denominarse un proceso de gentrificación cultural y comercial del Malecón Simón Bolívar, rebautizado en 1996, hace veintiún años desde la segunda alcaldía socialcristiana, como Malecón 2000.

Para efectos de este estudio tomaremos a Ciccolella (2011) como referencia sobre gentrificación aplicada a la apropiación cultural o comercial del espacio público central que implica el malecón. 
Un porcentaje significativo de autores que tratan sobre la gentrificación de las ciudades desarrolla principalmente los aspectos residenciales, que son de interés en las estadísticas habitacionales y los referentes en el momento de presentar planes y programas urbanos de vivienda en áreas centrales. El espacio público, el área social de la ciudad, por ser considerado precisamente como "público" es utilizado en los estudios urbanos como asunto técnico, esto es, dentro de los usos de suelo, como áreas de recreación de acceso libre, como parte del zoning y, en definitiva, como normativa urbana. Dicho de otro modo, los espacios públicos se han desligado del análisis de los procesos de gentrificación. Nuestro planteamiento, en cambio, es que se ha dado una gentrificación sui géneris el del Malecón Simón Bolívar.

Ya antes nos referimos al inicio de un fenómeno de gentrificación del centro de la ciudad, esto es, el abandono residencial por parte de sectores de menores recursos y la ocupación de los espacios por segmentos socioeconómicos altos, fenómeno que duró hasta la primera mitad del siglo pasado. Este proceso de gentrificación tuvo su clímax en los booms cacaoteros y bananeros. Los sectores pobres fueron poco a poco desalojados del centro y el área fue ocupada por los beneficiarios de estos auges económicos. Pero para la segunda mitad del siglo XX esta situación se revirtió: existió un abandono residencial de las élites guayaquileñas del centro de la ciudad, aun cuando se mantuvo la propiedad en muchas de las edificaciones. Estos sectores altos y medio altos resolvieron y resuelven las funciones que cumple el espacio público a través de clubes sociales, centros deportivos, canchas, piscinas, salones y demás espacios recreativos privados, algunos dentro de sus propias urbanizaciones cerradas donde emigraron, y otros lo resolvieron mediante clubes con derecho de admisión.

La nueva gentrificación que se da en el centro de Guayaquil, para fines de la segunda mitad del siglo pasado no está enlazada a la residencia, valor de uso de los nuevos sectores socio-económicos en el lugar, sino a la propiedad de la tierra como mercancía, valor de cambio. En el casco urbano, las élites mantienen la propiedad de las edificaciones y los negocios bancarios, comerciales y empresariales que en ellos desarrollan sus actividades. También gestionan, a través del capital inmobiliario, la compra de los solares y las propiedades del centro que dueños pobres venden porque no pueden mantenerlas debido a los altos costos de las refacciones y por las imposiciones tributarias o por constituirse en mercancías cuyo valor de cambio los obliga a vender y trasladarse a las áreas llamadas en el país marginales o barrios suburbanos.

La gentrificación, entonces, para el caso del centro de Guayaquil, no trajo aparejada una importante ocupación por las nuevas élites. Se evidenció una intención del capital inmobiliario de adquirir predios centrales para programas de vivienda de los nuevos sectores emergentes. Pero, en el momento del intercambio propio de una mercancía de lenta recuperación de capital, este se lentificó aún más, se desaceleró y se paralizó, pues en el centro, a medida que se iban deteriorando ciertas zonas, se iba perdiendo plusvalía y alejando inversiones.

Las élites abandonaron el área céntrica, mantuvieron sus propiedades y generalmente se vincularon a la administración y gestión de las ciudades, lo que les permitió mantener la hegemonía local o nacional; de ese modo, demandaron el control sobre el valor de uso y el valor de cambio del espacio público del Malecón, del que precisamente ellos y sus familias no hacen uso, sino que lo requieren para valorar el capital inmobiliario invertido y para invertir en el casco urbano. Y como las orillas del río son propiedad del Estado y el Malecón, el espacio público más icónico de la ciudad, implementaron dispositivos que han abonado, en la práctica, a una gentrificación sui géneris: cultural y comercial. Las élites van a dictar el cómo, cuándo, dónde, para qué y para quiénes es este espacio público. La pregunta que buscamos responder es cómo lo han logrado sin tener la propiedad privada del Malecón.

La respuesta la encontramos en el paso desde las propuestas de las unidades ejecutoras implementadas en la presidencia de León Febres Cordero (1984-1988) y aplicadas en la provincia 
del Guayas desde la gobernación de Jaime Nebot al nuevo modelo de gestión que se presenta junto con la imagen objetivo del PM2000. Ciertamente, las investigaciones realizadas desde la academia sobre el PM2000 indicaron con claridad que el modelo de gestión planteado por la administración municipal de Febres Cordero entre los años 1996-2000 -reforzado y ampliado por la administración de Nebot desde el año 2000 hasta el presente- extiende esta privatización en tres sentidos: (a) desde la construcción de la obra, hasta su gestión y administración; (b) desde el PM2000 hacia todo el proceso de regeneración urbana de Guayaquil; y, (c) en el caso del PM2000, desde la aprobación del contrato de concesión a 99 años para la administración y mantenimiento de esta franja de dos kilómetros y medio de la orilla del río Guayas en favor de la Fundación Malecón 2000 hasta la posibilidad de duplicación de dicho tiempo.

Con esta última decisión, la Municipalidad de Guayaquil entregó a la institución privada Fundación Malecón 2000 el borde ribereño del río que por ley está bajo jurisdicción y vigilancia de la Armada del Ecuador. El dispositivo de control para el manejo de la concesión está dado en la integración del directorio de la Fundación, presidido por el Alcalde de la ciudad, de todas las instituciones nacionales y provinciales, incluida la misma Armada, que tienen que ver con el sitio y con sus funciones: jurisdicción, administración, seguridad, control y demás aspectos inherentes a ellos. La gentrificación de este espacio público requirió efectivizarse mediante diversas disposiciones de diseño, financieras, administrativas, publicitarias en torno a los aspectos comerciales y culturales.

El Malecón Simón Bolívar estuvo, y debiera siempre estar, íntimamente vinculado al casco central de Guayaquil. Desde su fundación y hasta 1996 durante sus largos 176 años fue así. Aun cuando en determinadas épocas hubo edificios residenciales abandonados e inseguridad en el centro de la ciudad, no existieron cercas que separaran el Malecón de las edificaciones y funciones asentadas al otro lado de la Avenida, que aislaran el área de resi- dencia, de comercio y de gestión central del espacio público más representativo de Guayaquil.

En adelante vamos a trabajar la relación espacio público y sociedad porque el poder no se ejerce siempre de un solo lado, también se lo ejerce desde la ciudadanía cuya participación se ha caracterizado por una oscilación entre la aceptación y el aval de esta hegemonía y por la resistencia a determinadas prácticas, para ello han propuesto alternativas, 0 bien han ejercido acciones directas en respuesta a estas.

La oferta de consumo y los consumidores del espacio público

David Harvey (2012), en su libro Espacios de esperanza, resumió el papel del consumo:

Los capitales, productivo, financiero, inmobiliario y mercantil tienen sus propias modalidades de movimiento, y la circulación de las rentas burguesas genera complejas relaciones entre «necesidades», "deseos»y «lujos» que afectan a las decisiones sobre el estilo de vida, a los símbolos de estatus y a las modas establecidas por los ricos, los poderosos y los famosos. Estos establecen criterios relativos para los pobres... el sentido de bienestar es una medida comparativa más que absoluta (pp. 138-139).

Algunos guayaquileños, como consumidores del espacio público, han aceptado y avalado las obras de regeneración, no como obras impulsadas por los ciudadanos para ser ejecutadas por las autoridades de turno, sino como resultado de la decisión del alcalde. A quienes con su salario 0 sueldo pueden hacer uso de bienes y servicios que se ofertan en el mercado, este consumo les permite recuperar su fuerza de trabajo para estar disponible en la circulación del capital variable. Uno de los consumos tiene que ver con lo que brinda la ciudad para el disfrute del tiempo libre. 
De allí que los urbanistas en sus planificaciones tengan en cuenta determinadas normativas que se refieren a los usos del suelo para el acceso de todos los habitantes al espacio público. Por el lado de las políticas públicas, el paraguas regulatorio mayor es la Constitución de la República. La administración pública nacional y local se maneja con los planes de desarrollo del Estado, los primeros, y con los planes urbanos, los segundos. El PM2000, desde 1997, se ha convertido en un espacio público de gestión y manejo administrativo y financiero privado (FM2000, 2008), sistemáticamente, y cada vez más privatizado en los procesos comerciales y culturales. Para demostrar esta gentrificación del espacio público se describe brevemente los servicios y bienes comerciales y culturales que se desarrollan en este espacio público bajo la responsabilidad de la FM2000, que da cuenta del nivel de apropiación privada del espacio para dichos usos.

El sector comercial: en un recorrido sur-norte, el sector comercial del Malecón va desde la calle Cuenca hasta la calle 10 de Agosto e incluye los siguientes edificios importantes: el Mercado Artesanal, el Palacio de Cristal, la Plaza Olmedo, el Club de la Unión y el Centro Comercial Malecón. Se divide en tres subsectores: Antiguo Mercado Sur (hoy Palacio de (ristal); la Plaza Olmedo con el patio de comidas y el Centro Comercial Malecón 2000.

El sector cívico: el sector cívico del Malecón se desarrolla paralelo a la zona financiero-administrativa del casco central donde están ubicadas las principales instituciones de gestión administrativa y financiera de la ciudad desde la calle 10 de agosto hasta la calle Orellana (acera sur). Se divide en dos subsectores: la Plaza Cívica y el área recreativa, especialmente para niños. El primero comprende los espacios y plazoletas como la Rotonda con las estatuas de Simón Bolívar y San Martín y los monumentos de guayaquileños expresidentes de la república o personajes representativos, así como el ágora para presentaciones artísticas, que va de la calle 10 de Agosto a la 9 de Octubre; el segundo dispone de juegos infantiles, avanza desde la calle Francisco de P. Ycaza hasta la calle Orellana.

El sector cultural: se inicia en la calle Orellana (acera norte) y llega hasta el sector de Las Peñas. Se divide en dos subsectores: (a) los jardines del Malecón, desde la calle Orellana hasta la calle Juan Montalvo, y (b) el IMAX, el Centro Cultural Simón Bolívar, el MAAC, y el patio de comidas de la Calle Juan Montalvo hasta la explanada con los cañones, que se conoce como El Fortín de la Planchada, inicia de la calle Numa Pompilio Llona, entrada al barrio Las Peñas.

Habiendo compatibilidad, en términos generales, entre los usos del suelo de la zona central de la ciudad y la zonificación del PM2000 interesa develar si la relación espacio público y ciudadanía (sociedad, usuarios) obedece a una gestión urbana orientada a devolver buenas condiciones de habitabilidad a la población del centro de la ciudad al combinar usos de suelo, dar prioridad al diseño de un espacio público que responda al objetivo de revitalizar el casco urbano central, como indicó Wong (2005), 0 si, por el contrario, se ha generado un proceso de gentrificación del Malecón Simón Bolívar como se plantea en la hipótesis de este trabajo.

\section{Las ofertas comerciales y culturales del PM2000}

Apoyados en borradores de planos que entrega la FM2000, se hizo un listado de las ofertas comerciales y culturales de este proyecto, siempre en sentido sur-norte; se resumen a continuación.

\section{Las ofertas comerciales y culturales en el sector sur}

Mercado Artesanal, Centro de Exposiciones Palacio de Cristal, Parqueos de estacionamiento de carros, patio de comidas, máquinas dispensadoras de snacks y de bebidas, Centro Comercial Male- 
cón 2000 con dos plantas y una terraza con patio de comidas, Restaurante Mc Donald's, dos restaurantes más, embarcadero Buque Morgan para paseos turísticos, laguna con juegos infantiles.

\section{Las ofertas comerciales y culturales en el sector} central

Ingreso a parqueo de estacionamientos, máquinas dispensadoras de snacks y de bebidas, ágora que se alquila para presentaciones artísticas, plataforma del Hemiciclo que se alquila varias veces al año para localizar quioscos 0 estands de promoción de negocios comerciales diversos, área de juegos infantiles pagos, pista de autos infantiles (pagos), restaurantes incluidos los dos restaurantes construidos el 2016.

\section{Las ofertas comerciales y culturales en el Sector} Norte o Cultural

Jardines del Malecón que se alquilan para determinados eventos pagos, embarcadero fluvial de turismo, restaurante, parqueos de estacionamiento vehicular, venta de plantas, Imax (ahora Cine Malecón), Museo Miniatura de la historia de la ciudad (pago), Noria "La Perla", veta de artículos varios y comidas, discoteca.

A estos espacios más formales de los principales emprendimientos que generan ingresos a la
FM2000 deben sumarse otros más pequeños, localizados a lo largo del Malecón, como limpiadores de calzado y fotógrafos que se ofertan especialmente en el sector central, caricaturistas y retratistas lo largo del malecón y varios quioscos y máquinas dispensadoras de refrescos y snacks, cajeros automáticos.

Los costos de alquiler de los espacios edificados que oferta la FM2000 salen en su página web. Como ejemplo, un espacio para restaurante 0 cafetería puede costar mensualmente como mínimo 20 dólares por metro cuadrado, durante los diez años que dura el contrato, más diez cuotas ordinarias y una extraordinaria. Este ejemplo expresa la dinámica de la apropiación comercial del Malecón, si multiplicamos estos valores con relación a todos y cada uno de los espacios comerciales que se han detallado la suma es millonaria. Todos estos espacios se alquilan y son áreas seguramente no contabilizadas dentro del $20 \%$ de áreas construidas el Malecón y que ocupan el área del negocio más el área de acción de los consumidores, espacios que restan y complican la circulación de los peatones.

El PM2000 con esta gentrificación, convierte al Malecón Simón Bolívar en un sitio en el que proliferan ofertas de espacios comerciales y de servicios, además está separado del casco central por medio de rejas que no sirven al objetivo central que se planteó cuando se lo propuso: la revalorización de toda el área urbana central.

\section{Conclusiones}

La Regeneración Urbana del Malecón, primer proyecto diseñado, ejecutado y administrado por una institución de derecho privado en terrenos públicos, logra, en estas condiciones, salir adelante en plena crisis financiera y de dolarización del año 2000. Los sectores privados que operaron en el Malecón capitalizaron sus negocios, no la obra del Malecón. A los dispositivos financieros se unen ordenanzas y disposiciones cívicas, sociales y urbanas que profundizan la privatización del espacio público. Estos, a su vez, van acompañados de una campaña de comunicación intensiva que maneja los imaginarios del desarrollo de Guayaquil desde y por los guayaquileños, construyéndolo a partir de las institucionalidades locales y con aceptación por parte de la ciudadanía. Los dispositivos retóricos sobre el Malecón y sobre sus monumentos y edificaciones patrimoniales más representativas, el leitmotiv de la Regeneración Urbana, realmente esconden un proceso de gentrificación del espacio público. 
Desde principios del siglo XX hasta mediados, los usuarios del Malecón fueron mayoritariamente habitantes del centro 0 trabajadores y empleados ligados a las actividades portuarias y del astillero. Después del traslado del puerto y hasta antes de la Regeneración Urbana, aún era el lugar de paseo o de descanso de quienes habían emprendido actividades comerciales, bancarias, administrativas y de gestión en el centro de la ciudad. Era el sitio elegido para pasear por los residentes que aún vivían en el centro y un espacio recreativo preferencial, durante los fines de semana y fechas conmemorativas cívicas o religiosas, de una gran cantidad de pobladores que venían de los diversos sectores de la ciudad.

La Fundación Malecón 2000, que buscó "propiciar la regeneración urbana del centro de la ciudad y evitar el deterioro y pérdida de valor de las inversiones inmobiliarias de la zona adyacente al Malecón, generar empleo directo e indirecto, todo para el mejoramiento económico, social y ambiental" (FM2000, 2008, p. 24), no ha logrado este objetivo. El abandono residencial del área céntrica se agravó con un Malecón que le da la espalda al río y que a la vez, con las rejas, crea una barrera que impide su integración con el centro. № se ha vuelto a generar valor en el casco urbano central. Las expectativas abiertas para la inversión inmobiliaria con el PM2000 mantienen algunos terrenos ocupados como playas de estacionamientos en espera de la anhelada rehabilitación del área céntrica. El Malecón constituye un espacio público privilegiado por ser puerto, sitio fundacional de la ciudad, de gran accesibilidad y centralidad y dotado de infraestructura y de equipamiento urbano. Su condición de propiedad pública debiera garantizar el acceso libre de toda la población.

El Municipio de Guayaquil inaugura con esta obra su proceso de Regeneración Urbana. De un proyecto que buscaba volver a otorgar valor en el centro de la ciudad, rescatar los monumentos históricos y edificaciones patrimoniales, revitalizar la relación con el río y producir recursos para no depender de los fondos públicos, pasó a ser un proyecto que obstruye la relación directa del casco central con el Malecón y su frente de agua, crea pocas ofertas para el libre disfrute del espacio público, especialmente a la población residente en el centro, ejerce el control y la vigilancia de sus visitantes desde un espacio tratado cual panóptico, maneja con artificios la superficie construida para las concesiones comerciales y ha montado una estructura orgánico institucional y un marco jurídico en extremo privatizador.

El proyecto ha sido exitoso en el objetivo de generar recursos, pues, además de la administración y mantenimiento del Malecón, genera ingresos para diseñar y administrar las obras de regeneración urbana en otros sectores de la ciudad que se ejecutan a través de la Fundación Siglo XXI. Este objetivo conduce a encerrar en una cerca toda el área del Malecón para cuidarlo como se hace con un bien privado. También alienta la construcción de nuevas obras y nuevas concesiones comerciales, exacerbando la gentrificación comercial y cultural, en detrimento de la relación con el río, que va a ser la gran deuda que se tenga con la ciudad, sus habitantes y su frente de agua.

El proyecto debe alentar la utilización del espacio por los ciudadanos. A medida que caminan, usan y recorren se conformen travesías propias, que se constituya en un espacio no exterior al sujeto, sino apropiado por él, que reconfigura la relación de los hombres entre sí y que se opone al orden hegemónico espacial en pro de la construcción de una sociedad diversa, igualitaria y democrática.

La ciudadanía ha comenzado a responder muy tímidamente a esta gentrificación. Primero fue la academia con los estudios de Chancay y Uscocovich (2002), Andrade (2005) y Navas (2012). Luego fueron las instituciones culturales y los sectores informales. Incluso ha habido respuestas individuales al abuso de los sectores que cuidan la seguridad del Malecón. Pero han faltado respuestas contundentes de la ciudadanía. Con las inauguraciones de las primeras etapas los guayaquileños aplaudimos las mejoras y hemos avalando la obra municipal. En las relaciones de poder la hegemonía estuvo en el gobierno local. Pero el Malecón es un proyecto que no acaba, que siempre está inaugurando nuevas obras. La situación es tal que las críticas aisladas han comenzado a hacerse escuchar, pues mientras más crece la oferta comercial (este mes sale la 
convocatoria a participar en la construcción del reforzamiento estructural en plataforma de entretenimiento -proyecto safari xtreme- en el malecón Simón Bolívar) más crecen las rejas que cercan al Malecón y lo apartan de su área central y también crece la inconformidad de la ciudadanía.

\section{Recomendaciones}

Las Facultades de Arquitectura de la ciudad de Guayaquil deberían ser las primeras instituciones en pronunciarse frente a los problemas de la ciudad y están llamadas a orientar y proponer proyectos urbanos arquitectónicos que respondan a las necesidades, los intereses, la herencia cultural y social y los recursos financieros de la ciudad. Nuestra propuesta es dejar de disneylandizar el Malecón, quitar las rejas e integrarlo al casco urbano, convertir en peatonal la Avenida Simón Bolívar, construir parqueos para los departamentos residenciales en las transversales del malecón, implementar una vía para ambulancias, carros de bomberos y policías. Se debería devolver la vieja relación del centro con su río, el espejo de agua más grande del pacífico sur, explotar el área de contemplación natural y la vinculación de la ciudadanía con el agua, así como fomentar el transporte fluvial y los deportes acuáticos. Cumplir con el objetivo de la revalorización del área central convertiría a este espacio público en el complemento urbano de disfrute libre; La Perla y los espacios construidos refuncionalizarían al nuevo malecón para dejar que su mantenimiento se autofinancie y no se convierta en el recurso para la regeneración urbana de otras partes de la ciudad.

En el mejor de los casos, habría que acordar que en los últimos años de la concesión se agilite el paso de la privatización hacia nuevas formas de administración del espacio público en las que se dé prioridad al manejo de las instituciones culturales de la ciudad como la venta de libros y revistas, el alquiler de revistas, las exhibiciones artísticas, los concursos de pintura, escultura, dibujo, música, bailes y demás expresiones artísticas. Además, se debería promover que el Palacio de Cristal, cerrado la mayor parte de tiempo, se convierta en el mercado público de frutas, flores, artesanías, pescados y mariscos que atraiga al público, especialmente al sector residencial del centro, es decir, en un mercado que exhiba productos en sus múltiples colores y sabores y recoja las tradiciones de antaño en un nuevo marco de orden y salubridad.

En definitiva, se considera preciso devolver el espacio público más emblemático de Guayaquil a la administración pública municipal con dispositivos que centren su accionar en su ocupación libre, su vista al río y su lugar para dar cabida a la diversidad de su población.

\section{Referencias bibliográficas}

AHG. (1972). Revista del Archivo Histórico del Guayas, núm. 2, Guayaquil.

Andrade, X. (2005). Guayaquil: renovación urbana y aniquilación del espacio público. En Carrión, F.

(Ed): Regeneración y revitalización urbana en las Américas: hacia un Estado estable. Quito: FLACSO.

Avilés, E. y Hoyos, M. (2006). Historia de Guayaquil. Municipalidad de Guayaquil.

Blacio, M., Chalen, G., Pazmiño, D. y Ponce, M. (1983). Alternativa popular frente a la crisis urbana. Ponencia en el Congreso de Arquitectos del Ecuador. Guayaquil: Universidad de Guayaquil.

Blacio, M. (1997). Diagnóstico socio económico y análisis de los posibles impactos. Evaluación del impacto ambiental para el Proyecto Malecón 2000. Guayaquil: INOCAR/Fundación Malecón 2000. 
Cárdenas, E. (1999). Uso y significado del espacio público. Arquitectura y Urbanismo, No. 3. La Habana, Cuba: ISPJAE.

Carrión, F. (1986). Proceso de urbanización en el Ecuador (del siglo XVIII al siglo XX). Antología, CIUDAD. Quito: Editorial El Conejo.

Carrión, F. (2005). Regeneración y revitalización urbana en las Américas: hacia un Estado estable. Quito: FLACSO.

Carrión, F. (2010). Ciudad, memoria y proyecto. Quito: OLACCHI, Municipio Metropolitano de Quito.

Carrión, F. y Hanley, L. (ed). (2005). Regeneración y revitalización urbana en las Américas: hacia un Estado estable. Quito: FLACSO.

Chancay, M. A. y Uscocovich, V. (2002). El consumo cultural del espacio público de jóvenes de sectores populares en la regeneración urbana: caso Malecón 2000. Guayaquil: Universidad Casa Grande.

Ciccolella, P. (2011). Metrópolis latinoamericanas: más allá de la globalización. Quito: OLACCHI. Municipio Metropolitano de Quito.

Estrada Ruiz, J. (1999). El Malecón. Rescatando la Historia. Construyendo el futuro. Guayaquil: Fundación Malecón 2000.

Estrada Ruiz, J. (2013). Las Carretillas del Malecón. En Memorias Porteñas, Revista de Diario Expreso del 11 de agosto de 2013, tomado del libro de Estrada, Jenny, El tiempo de la yapa.

Estrada Ycaza, J. (1996). Guía Histórica de Guayaquil, Tomo 2. Guayaquil: Poligráfica.

Estrada Ycaza, J. (2000). Guía Histórica de Guayaquil, Tomo 1. Edición corregida y aumentada. Guayaquil: Poligráfica.

Estrada Ycaza, J. (2000). Guía Histórica de Guayaquil, Tomo 3. Guayaquil: Poligráfica.

Estrada Ycaza, J. (2007). Guía Histórica de Guayaquil, Tomo 4. Guayaquil: Poligráfica.

Estrada Ycaza, J. (2008). Guía Histórica de Guayaquil, Tomo 5. Guayaquil: Poligráfica.

Fernández, A. y Fernández, A.M. (2007). Urban Regeneration in Guayaquil. 43rd ISoCaRP Congress. Urban trialogues. Coproductive ways to relate visioning and strategic urban projects.

Fundación Malecón 2000.(2008). El Guayaquil del nuevo milenio. Guayaquil: Trama Ediciones.

Harvey, D. (2012). Espacios de Esperanza. Madrid: Ediciones Akal.

Navas, G. (2012). Malecón 2000, el inicio de la regeneración urbana en Guayaquil, un enfoque proyectual. Quito: FLACSO.

Wong, D. (2005). Regeneración urbana. Marca de Guayaquil. Guayaquil: Poligráfica.

Notas

${ }^{1}$ Parte de la tesis doctoral en desarrollo titulada Espacio público y relaciones de poder: el caso de Malecón 2000, Doctorado FADU-UBA.

${ }^{2}$ Los vecinos del Astillero, para diciembre de ese año, habían colectado ocho mil sucres para que la obra se colocase en la calle Saraguro (hoy Av. Olmedo); la comunidad de Las Peñas ponía esa misma cantidad para que fuese ubicada en la Plaza de La Concepción (hoy Plaza Colón), al norte. En sesión del 8 de julio de 1892, el comité pro monumento decidió que fuese colocado en la calle Saraguro y fue recién en 1950 reubicado en la misma Av. Olmedo, en intersección con el Malecón. Nótese la participación vecinal de dos barrios que disputaban el lugar del monumento y cómo cada comunidad pretendió financiar la obra pública. 
${ }^{3}$ Señalar a los ladrones y gente de mal vivir como los culpables del abandono del centro y del malecón es esconder las graves deficiencias de una falta de planificación del crecimiento de la ciudad y de una complicidad entre el poder económico y el poder político administrativo y poner como causas lo que realmente son efectos de esta imprevisión.

${ }^{4}$ Guayaquil ha tenido cinco proyectos de planificación (1967, 1972, 1973-74, 1975, 1985-87). Ninguno se concretó. El de 1975 tuvo la Ordenanza Preventiva, el Esquema Urbano de Guayaquil, que tampoco se cumplió. Propuso, entre otros aspectos, que la zona del Malecón Simón Bolívar fuese destinada a terminal fluvial de pasajeros, a mejorar muelles y su estructura física, a la rehabilitación, remodelación, restauración, renovación, relocalización o acciones combinadas de desarrollo de los Cerros Santa Ana y El Carmen, que comprendía el cementerio de Guayaquil, antiguas canteras municipales, antigua cárcel pública, Hospital Luis Vernaza, mirador de la ciudad, Plaza Colón, Barrio Las Peñas, áreas residenciales de los Cerros, El Fortín, la Cervecería. Para 1995 la Ordenanza del esquema urbano de Guayaquil admitía que en el Centro de la ciudad las actividades de gestión administrativa, tanto municipal como provincial, y las matrices bancarias del sistema financiero seguían siendo una fuerza centrípeta (Municipio de Guayaquil: Ordenanza, Registro Oficial, Quito, 20 de diciembre de 1995). 